\title{
Identifikasi Bidang Gelincir dan Tipe Tanah Longsor di Daerah Rawan Longsor Desa Bantai Menggunakan Metode Geolistrik
}

Hendria $^{*}$, Irfana Diah Faryunia , Zulfiana

\author{
aProgram Studi Geofisika, Jurusan Fisika, Fakultas Matematika dan Ilmu Pengetahuan Alam \\ Universitas Tanjungpura \\ Jalan Prof. Dr. H. Nawawi, Pontianak, Indonesia \\ *Email : hendrihamidi3511@gmail.com
}

\begin{abstract}
Abstrak
Pada penelitian ini, telah diidentifikasi bidang gelincir dan tipe tanah longsor yang terdapat pada Desa Bantai Kecamatan Bonti Kabupaten Sanggau dengan menggunakan metode geolistrik konfigurasi WennerSchlumberger. Pengambilan data dilakukan pada empat lintasan. Panjang setiap lintasan adalah 117 meter, sedangkan jarak elektroda terkecil adalah 3 meter. Hasil analisa penampang resistivitas dua dimensi (2D) dari empat lintasan menunjukkan bahwa bidang gelincir tanah longsor berupa batu gamping dengan nilai resistivitas antara $945 \Omega \mathrm{m}$ sampai $3518 \Omega \mathrm{m}$. Bidang gelincir tanah longsor di daerah penelitian terdapat pada kedalaman 1-12 meter dengan tipe tanah longsor berupa tipe translasi.
\end{abstract}

Kata Kunci : bidang gelincir, geolistrik, resistivitas, Wenner-Schlumberger

\section{Latar Belakang}

Kabupaten Sanggau merupakan salah satu kabupaten di Kalimantan Barat yang memiliki potensi tanah longsor yang tinggi [1]. Hal ini terjadi karena kondisi topografi Kabupaten Sanggau yang merupakan daerah dataran tinggi berbukit dengan lereng yang curam, sehingga daerah ini dapat terjadi gerakan tanah yang mengakibatkan terjadinya tanah longsor.

Desa Bantai, Kecamatan Bonti, Kabupaten Sanggau adalah salah satu contoh daerah perbukitan dengan kemiringan lereng yang curam yaitu berkisar $16^{\circ}-30^{\circ}$. Bukit di wilayah tersebut dimanfaatkan untuk perluasan jalan, pembuatan pemukiman warga, dan lahan perkebunan. Adanya pemanfaatan lahan membuat warga sekitar harus menyiapkan dan menata lahan agar tidak menimbulkan resiko atau bahaya seperti bencana tanah longsor.

Salah satu cara untuk menanggulangi bencana tanah longsor adalah dengan memprediksi bidang gelincir. Bidang gelincir adalah bidang yang menjadi landasan bergeraknya massa tanah. Bidang gelincir sendiri merupakan bidang yang kedap air. Kebanyakan material tanah longsor yakni lempung atau pasir, material ini mudah meresapkan air sehingga berpengaruh terhadap penyaluran air sampai ke bidang gelincir [2].

Metode yang sering dimanfaatkan dalam pendugaan bidang gelincir tanah longsor adalah metode geolistrik resistivitas. Metode ini memanfaatkan nilai resistivitas dari tanah untuk mengetahui lapisan bawah tanah. Kelebihan dari metode ini adalah tidak merusak lingkungan, biaya relatif murah dan mampu mendeteksi lapisan tanah hingga beberapa meter di bawah permukaan tanah [3].

Menurut Wakhidah (2014), metode geolistrik resistivitas konfigurasi WennerSchlumberger cocok digunakan untuk mengetahui struktur dan lapisan tanah karena dapat memonitor keadaan di bawah permukaan tanah secara vertikal dan horizontal [4]. Penelitian metode geolistrik resistivitas pada penelitian sebelumnya telah terbukti bahwa metode geolistrik dapat digunakan untuk pendugaan tanah longsor, seperti penelitian yang telah dilakukan oleh Heradian dan Arman (2015) yang berhasil mengidentifikasi bidang gelincir di Desa Aruk Kecamatan Sajingan Besar Kabupaten Sambas dengan menggunakan metode resistivitas konfigurasi Schlumberger. Berdasarkan nilai resistivitas dari 3,51 $\Omega \mathrm{m}-34,9$ $\Omega \mathrm{m}$ diidentifikasi bahwa bidang gelincirnya berupa tanah lempung [5]. Lismalini (2014) berhasil mengidentifikasi bidang gelincir berupa batu gamping menggunakan metode geolistrik konfigurasi Schlumberger dengan nilai resistivias sebesar $121 \Omega \mathrm{m}-273 \Omega \mathrm{m}[6]$.

Dalam penelitian ini telah dilakukan identifikasi bidang gelincir dan klasifikasi tipe tanah longsor di daerah rawan longsor Desa Bantai menggunakan metode geolistrik.

\section{Metodologi}

\subsection{Metode Geolistrik Resistivitas}

Metode geolistrik adalah suatu teknik investigasi dari permukaan tanah untuk mengetahui lapisan-lapisan batuan atau material berdasarkan pada prinsip bahwa lapisan batuan atau masing-masing material mempunyai nilai 
resistivitas atau hambatan jenis yang berbedabeda. Tujuan dari survei geolistrik adalah untuk menentukan distribusi nilai resistivitas dari pengukuran yang dilakukan di permukaan tanah.

Harga resistivitas suatu bahan dapat dituliskan dengan persamaan 1 sebagai berikut [7]:

$$
\rho=\frac{V}{I} \frac{A}{L}
$$

dimana $V$ adalah tegangan yang diukur (V), I adalah kuat arus yang diukur (A), $\rho$ adalah resistivitas bahan $(\Omega \mathrm{m}), L$ adalah panjang medium (m) dan $A$ adalah luas penampang $\left(\mathrm{m}^{2}\right)$.

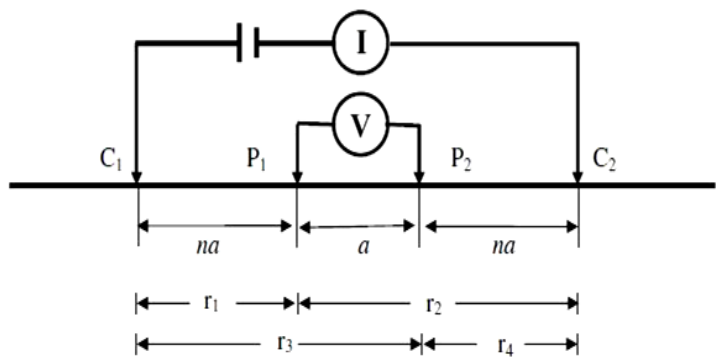

Gambar 1. Susunan elektroda arus dan tegangan konfigurasi Wenner-Schlumberger [7]

Penelitian ini menggunakan metode geolistrik konfigurasi Wenner-Schlumberger. Susunan elektroda konfigurasi WennerSchlumberger terlihat pada Gambar 1. Pengukuran di lapangan dengan metode geolistrik resistivitas menggunakan empat buah elektroda yang terdiri dari dua elektroda penginjeksi arus $\left(\mathrm{C}_{1}\right.$ dan $\left.\mathrm{C}_{2}\right)$ dan dua elektroda pengukur tegangan $\left(\mathrm{P}_{1}\right.$ dan $\left.\mathrm{P}_{2}\right)$. Secara umum, kedalaman pengujian dapat diperbesar dengan menambah jarak antara dua elektroda arus [8].

Nilai tegangan antara titik $\mathrm{P}_{1}$ dan $\mathrm{P}_{2}$ adalah:

$$
\begin{aligned}
\Delta V & =\left[\frac{I \rho}{2 \pi}\left(\frac{1}{r_{1}}-\frac{1}{r_{2}}\right)\right]-\left[\frac{I \rho}{2 \pi}\left(\frac{1}{r_{3}}-\frac{1}{r_{4}}\right)\right] \\
& =\frac{I \rho}{2 \pi}\left[\left(\frac{1}{r_{1}}-\frac{1}{r_{2}}\right)-\left(\frac{1}{r_{3}}-\frac{1}{r_{4}}\right)\right]
\end{aligned}
$$

dimana $\Delta V$ adalah tegangan antara $\mathrm{P}_{1}$ dan $\mathrm{P}_{2}(\mathrm{~V})$, I adalah kuat arus melalui elektroda $\mathrm{C}_{1}$ dan $\mathrm{C}_{2}(\mathrm{~A})$, $\rho$ adalah resistivitas bahan $(\Omega \mathrm{m}), r_{1}$ adalah jarak antara $\mathrm{C}_{1}$ dan $\mathrm{P}_{1}(\mathrm{~m}), r_{2}$ adalah jarak antara $\mathrm{C}_{2}$ dan $\mathrm{P}_{1}(\mathrm{~m}), r_{3}$ adalah jarak antara $\mathrm{C}_{1}$ dan $\mathrm{P}_{2}(\mathrm{~m})$ dan $r_{4}$ adalah jarak antara $\mathrm{C}_{2}$ dan $\mathrm{P}_{2}(\mathrm{~m})$.

\subsection{Resistivitas Semu}

Bumi terdiri dari lapisan-lapisan dengan nilai resistivitas yang berbeda-beda, sehingga tegangan yang terukur merupakan pengaruh dari lapisan-lapisan tersebut. Nilai resistivitas yang terukur bukan merupakan nilai resistivitas untuk satu lapisan saja dan juga bukan nilai resistivitas sesungguhnya. Pada pengukuran di lapangan, resistivitas yang terukur dikenal sebagai resistivitas semu $\left(\rho_{a}\right)$. Resistivitas semu merupakan resistivitas dari suatu medium fiktif homogen yang ekuivalen dengan medium berlapis yang ditinjau. Ilustrasi hal tersebut terlihat pada Gambar 2.
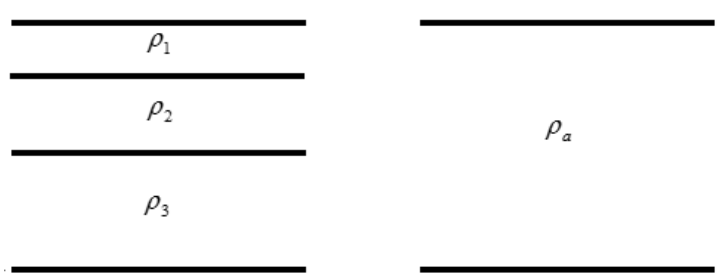

Gambar 2. Medium berlapis dengan variasi resistivitas [9]

Nilai resistivitas semu disetiap titik akan memiliki besar yang berbeda, sehingga menyebabkan bidang ekuivalen menjadi tidak beraturan. Berdasarkan persamaan 2, nilai resistivitas semu dapat dihitung dengan persamaan 3 [10]:

$$
\rho_{a}=K \frac{\Delta V}{I}
$$

$\mathrm{K}$ merupakan faktor geometri dengan satuan meter $(\mathrm{m})$. Nilai $\mathrm{K}$ berbeda-beda tergantung dengan konfigurasi yang digunakan dalam pengukuran. Berdasarkan persamaan 2 dan 3, maka nilai $\mathrm{K}$ dapat dihitung dengan persamaan 4 [7]:

$$
K=2 \pi\left(\frac{1}{r_{1}}-\frac{1}{r_{2}}-\frac{1}{r_{3}}+\frac{1}{r_{4}}\right)^{-1}
$$

Jika memasukkan jarak $r_{1}, r_{2}, r_{3}$ dan $r_{4}$ sesuai dengan Gambar 1, maka nilai $\mathrm{K}$ pada metode geolistrik konfigurasi WennerSchlumberger menjadi [11]:

$$
K=\pi n(1+n) a
$$

dimana $n$ adalah lapisan penelitian, $a$ adalah jarak elektroda terkecil (m),

\subsection{Akuisisi dan Analisis Data}

Penelitian ini dilakukan pada sebuah lokasi yang berada di bukit di Dusun Bantai, Desa Bantai, Kecamatan Bonti, Kabupaten Sanggau, Kalimantan Barat. Secara geografis wilayah tersebut terletak antara 00,5074020 00,5072910 LU dan $110,581468^{\circ}$ - 110,5819970 BT.

Pengambilan data dilakukan dengan cara menginjeksikan arus searah dan tegangan di atas permukaan tanah menggunakan alat Automatic Resistivity System (ARES) Multielectrode. Berdasarkan hasil penginjeksian akan didapat nilai resistivitas semu batuan yang dapat dimodelkan untuk menentukan bidang gelincir dan tipe tanah longsor. 


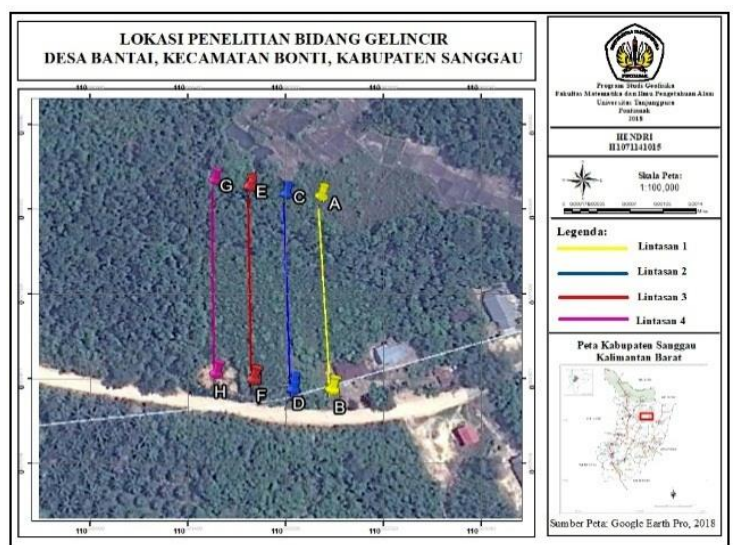

Gambar 3. Lokasi penelitian [12]

Pengambilan data geolistrik resistivitas pada penelitian ini menggunakan konfigurasi Wenner-Schlumberger untuk melihat penampakan posisi batuan di dalam bumi secara vertikal maupun horizontal. Berdasarkan Gambar 3, pengukuran di lokasi penelitian dilakukan pada 4 lintasan dengan panjang setiap lintasan adalah 117 meter. Jarak setiap lintasan sebesar 20 meter, jarak setiap elektroda (spasi) sebesar 3 meter dan luas lokasi penelitian adalah $120 \mathrm{~m}$ x $60 \mathrm{~m}$. Lintasan penelitian yang digunakan membentang dari arah utara ke arah selatan atau membentang dari bukit yang berada di sekitar sawah menuju ke arah jalan. Jarak lintasan dengan jalan berkisar 10 meter.

Pengambilan data di lapangan menghasilkan data resistivitas semu material yang kemudian diinversi dengan menggunakan perangkat lunak Res2Dinv versi 3.54 sehingga didapatkan citra penampang resistivitas 2D dari setiap lintasan. Interpretasi bidang gelincir dapat dilakukan dengan menganalisa nilai resistivitas 2D serta membandingkannya dengan nilai resistivitas beberapa material yang ditunjukkan pada Tabel 1 dan disesuaikan dengan peta geologi lembar Sanggau pada Gambar 8. Tipe tanah longsor diinterpretasi berdasarkan bentuk bidang gelincir dari citra penampang resistivitas 2D.

Tabel 1. Resistivitas beberapa material bumi

\begin{tabular}{ll}
\hline \multicolumn{1}{c}{ Batuan } & \multicolumn{1}{c}{ Resistivitas $(\Omega \mathrm{m})$} \\
\hline $\begin{array}{l}\text { Top soil (tanah penutup) } \\
\text { Consolidated shales }\end{array}$ & $250-1700$ \\
$\begin{array}{l}\text { (serpihan padat) } \\
\text { Lanau (Silt) }\end{array}$ & $10-200$ \\
$\begin{array}{l}\text { Batu pasir (sandstone) } \\
\text { Batu gamping }\end{array}$ & $1-6.4 \times 10^{3}$ \\
$\begin{array}{l}\text { (limestone) } \\
\text { Dolomite }\end{array}$ & $50-10^{7}$ \\
$\begin{array}{l}\text { Unconsolidated wet clay } \\
\text { (lempung basah tidak }\end{array}$ & 20 \\
padat) &
\end{tabular}

\begin{tabular}{ll}
$\begin{array}{l}\text { Lempung (Clay) } \\
\text { Lempung pasiran / }\end{array}$, $80-100$ \\
pasir lempungan (Sandy \\
clay / Clayey sand) \\
Andesit & $1,70 \times 10^{2}-4,5 \times 10^{4}$ \\
Kuarsa & $3 \times 10^{2}-3 \times 10^{5}$ \\
Alluvium dan pasir & $10-800$ \\
Pasir (Sand) & $1-10^{3}$ \\
Gravel (Kerikil) & $100-600$ \\
Granit & $3 \times 10^{2}-10^{6}$ \\
Diorit & $10^{4}-10^{5}$ \\
Gabro (Gabbro) & $10^{3}-10^{6}$ \\
Basal (Basalt) & $10-1,3 \times 10^{7}$ \\
Sekis (Schists) & $20-10^{4}$ \\
Pasir tuffan & $20-10^{2}$ \\
Air tanah & $0,5-3 \times 10^{2}$ \\
Air laut & 0,2 \\
\hline Sumber:[7]. &
\end{tabular}

Sumber: [7].

\section{Hasil dan Pembahasan}

\subsection{Analisis pada Lintasan 1}

Lintasan pertama membentang dari arah utara ke arah selatan. Posisi elektroda pertama terletak pada koordinat $00.508343^{\circ} \mathrm{LU}$ dan $110.582025^{\circ} \mathrm{BT}$ dengan elevasi sebesar $69 \mathrm{mdpl}$, sedangkan posisi elektroda terakhir berada pada koordinat $00.507291^{\circ} \mathrm{LU}$ dan $110.581997^{\circ} \mathrm{BT}$ dengan elevasi sebesar $59 \mathrm{mdpl}$. Ketinggian pada lintasan 1 berkisar antara 59 mdpl sampai 81 mdpl. Sudut kemiringan lereng lintasan 1 adalah 21,610 diklasifikasikan sebagai kemiringan lereng curam. Kemiringan lereng merupakan unsur topografi yang paling berpengaruh terhadap aliran permukaan dan erosi tanah.

Gambar 4 merupakan hasil inversi penampang resistivitas dua dimensi pada lintasan 1 menggunakan metode geolistrik resistivitas konfigurasi Wenner-Schlumberger. Berdasarkan citra penampang resistivitas 2D (Gambar 4), kedalaman pengukuran mencapai 23,6 meter dengan iterasi sebanyak 15 kali dan RMS-error sebesar 5,7 \%. Sedangkan rentang nilai resistivitas daerah penelitian bervariasi mulai dari $198 \Omega \mathrm{m}$ sampai $11121 \Omega \mathrm{m}$.

Jenis batuan pertama adalah batuan pasir lempungan (clayey sand) dengan rentang nilai resistivitas berkisar $198 \Omega \mathrm{m}-352 \Omega \mathrm{m}$. Jenis batuan kedua dengan rentang nilai resistivitas berkisar $626 \Omega \mathrm{m}-1113 \Omega \mathrm{m}$ dapat diasumsikan sebagai batu pasir (sandstone) dan tanah penutup (top soil).

Jenis batuan ketiga dengan rentang nilai resistivitas berkisar $1979 \Omega \mathrm{m}-3518 \Omega \mathrm{m}$ dapat diasumsikan sebagai batu gamping (limestone). Jenis batuan keempat dengan rentang nilai resistivitas berkisar $6255 \Omega \mathrm{m}-11121 \Omega \mathrm{m}$, sehingga diasumsikan sebagai batuan granit. 


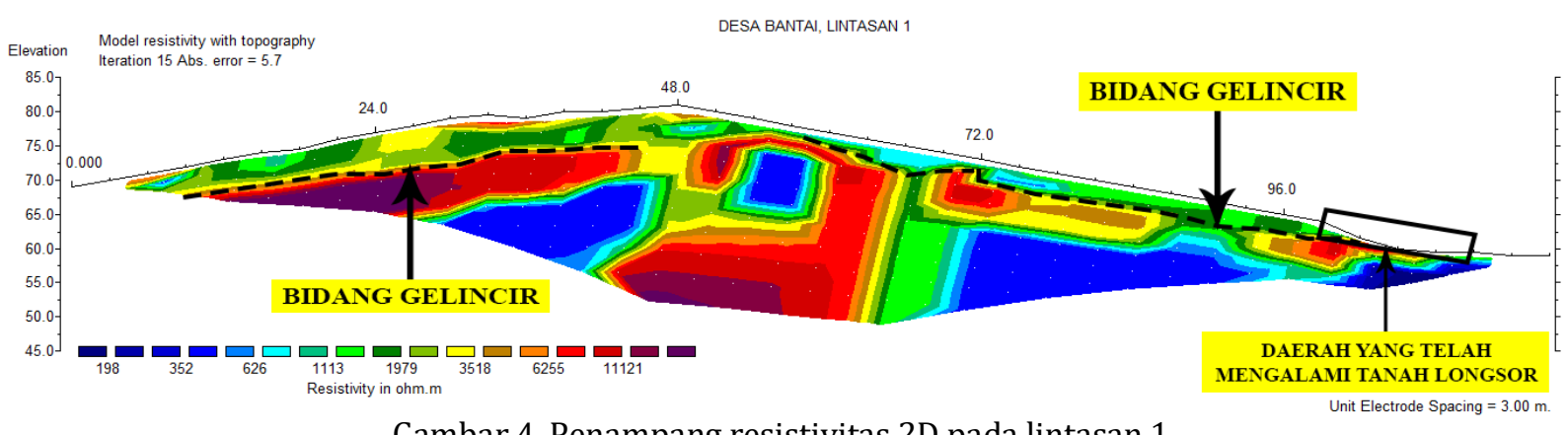

Gambar 4. Penampang resistivitas 2D pada lintasan 1

\subsection{Analisis pada Lintasan 2}

Lokasi lintasan kedua berjarak 20 meter dari lintasan pertama, membentang dari arah utara ke arah selatan. Posisi elektroda pertama terletak pada koordinat $00.508358^{\circ} \mathrm{LU}$ dan $110.581845^{\circ} \mathrm{BT}$ dengan elevasi sebesar $70 \mathrm{mdpl}$, sedangkan posisi elektroda terakhir berada pada koordinat $00.507302^{\circ} \mathrm{LU}$ dan $110.581818^{\circ} \mathrm{BT}$ dengan elevasi sebesar $60 \mathrm{mdpl}$. Ketinggian lintasan 2 berkisar antara $60 \mathrm{mdpl}$ sampai 83 mdpl. Sudut kemiringan lereng pada lintasan 2 adalah 20,96 diklasifikasikan sebagai kemiringan lereng curam, yang menyebabkan lintasan ini berpotensi untuk longsor.

Gambar 5 merupakan hasil inversi citra dua dimensi penampang resistivitas pada lintasan 2 menggunakan metode geolistrik resistivitas konfigurasi Wenner-Schlumberger. Berdasarkan citra penampang resistivitas 2D (Gambar 5), kedalaman pengukuran mencapai 23,6 meter dengan iterasi sebanyak 15 kali dan RMS-error sebesar 9,8 \%. Sedangkan rentang nilai resistivitas daerah penelitian bervariasi mulai dari $116 \Omega$ m sampai $11503 \Omega \mathrm{m}$.

Jenis batuan pertama adalah batuan pasir lempungan dengan rentang nilai resistivitas berkisar $116 \Omega \mathrm{m}-224 \Omega \mathrm{m}$. Jenis batuan kedua dengan rentang nilai resistivitas berkisar $431 \Omega \mathrm{m}$ - $832 \Omega$ m dapat diasumsikan sebagai batu pasir dan tanah penutup.

Jenis batuan ketiga memiliki rentang nilai resistivitas berkisar $1604 \Omega \mathrm{m}-3093 \Omega \mathrm{m}$ dapat diasumsikan sebagai batu gamping. Jenis batuan keempat memiliki rentang nilai resistivitas berkisar $5965 \Omega \mathrm{m}$ - $11503 \Omega \mathrm{m}$, sehingga diasumsikan sebagai batuan granit.

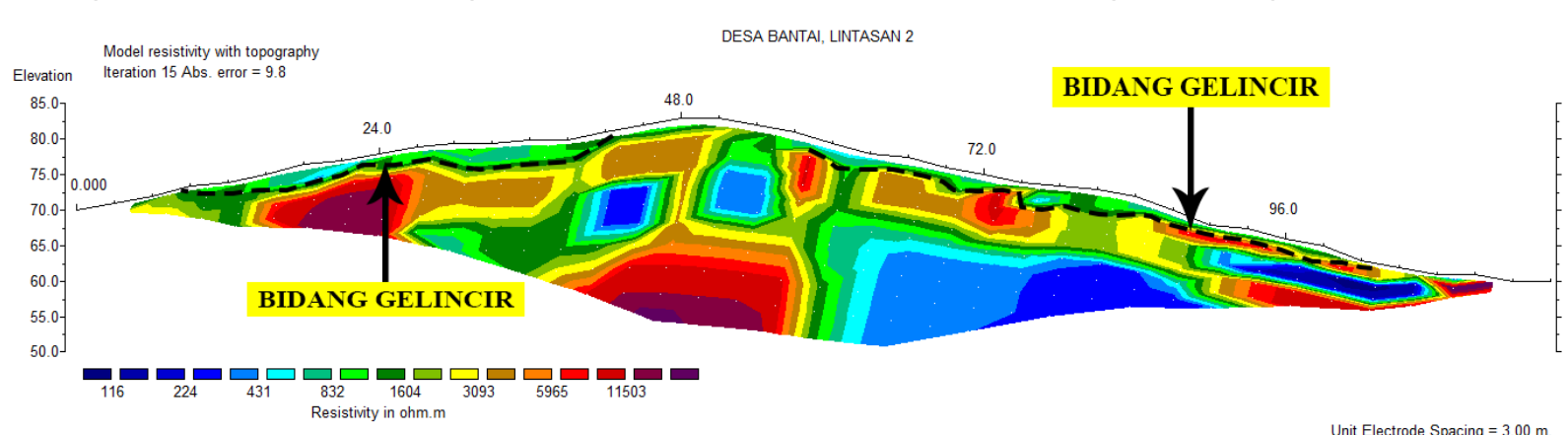

Gambar 5. Penampang resistivitas 2D pada lintasan 2

\subsection{Analisis pada Lintasan 3}

Lokasi lintasan ketiga berjarak 20 meter dari lintasan kedua, membentang dari arah utara ke arah selatan. Posisi elektroda pertama terletak pada koordinat $00.508411^{\circ} \mathrm{LU}$ dan $110.581665^{\circ}$ BT dengan elevasi sebesar $75 \mathrm{mdpl}$, sedangkan posisi elektroda terakhir berada pada koordinat $00.507362^{\circ} \mathrm{LU}$ dan $110.581641^{\circ} \mathrm{BT}$ dengan elevasi sebesar $61 \mathrm{mdpl}$. Ketinggian lintasan 3 berkisar antara $61 \mathrm{mdpl}$ sampai $82 \mathrm{mdpl}$. Sudut kemiringan lereng dari lintasan 3 adalah 18,970 diklasifikasikan sebagai kemiringan lereng curam, yang menyebabkan lintasan ini berpotensi untuk longsor.

Gambar 6 merupakan hasil inversi citra dua dimensi penampang resistivitas pada lintasan
3 menggunakan metode geolistrik resistivitas konfigurasi Wenner-Schlumberger. Berdasarkan citra penampang resistivitas 2D (Gambar 6), kedalaman pengukuran mencapai 23,6 meter dengan iterasi sebanyak 15 kali dan RMS-error sebesar 7,1\%. Sedangkan rentang nilai resistivitas daerah penelitian bervariasi mulai dari 88,9 $\Omega$ m sampai $9954 \Omega \mathrm{m}$.

Jenis batuan pertama adalah batuan pasir lempungan dengan rentang nilai resistivitas berkisar 88,9 $\Omega \mathrm{m}-174 \Omega \mathrm{m}$. Jenis batuan kedua dari warna biru cerah sampai hijau muda memiliki rentang nilai resistivitas berkisar 342 $\Omega \mathrm{m}-671 \Omega \mathrm{m}$ diasumsikan sebagai batu pasir dan tanah penutup. 
Jenis batuan ketiga dari warna hijau tua sampai warna cokelat memiliki rentang nilai resistivitas berkisar $1318 \Omega \mathrm{m}-2585 \Omega \mathrm{m}$ dapat diasumsikan sebagai batu gamping. Jenis batuan keempat dari warna jingga sampai warna unggu gelap memiliki rentang nilai resistivitas berkisar $5073 \Omega \mathrm{m}$ - $9954 \Omega \mathrm{m}$, sehingga diasumsikan sebagai batuan granit.

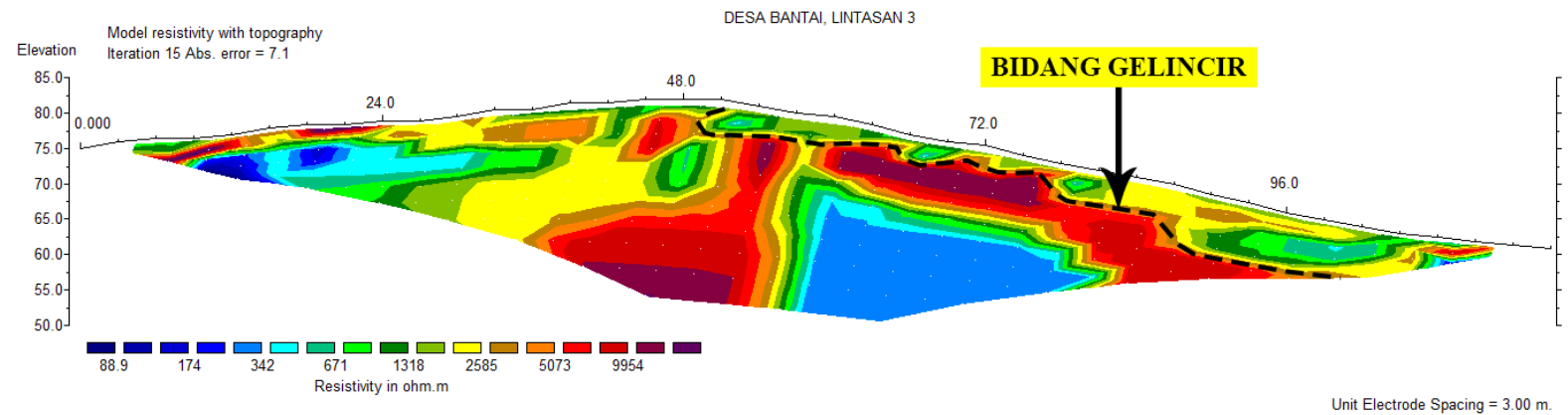

Gambar 6. Penampang resistivitas 2D pada lintasan 3

\subsection{Analisis pada Lintasan 4}

Lokasi lintasan keempat berjarak 20 meter dari lintasan ketiga, membentang dari arah utara ke arah selatan atau membentang dari bukit yang berada di sekitar kebun warga menuju ke arah jalan. Posisi elektroda pertama terletak pada koordinat $00.508454^{\circ} \mathrm{LU}$ dan $110.581485^{\circ} \mathrm{BT}$ dengan elevasi sebesar 75 mdpl, sedangkan posisi elektroda terakhir berada pada koordinat $00.507402^{\circ} \mathrm{LU}$ dan $110.581468^{\circ} \mathrm{BT}$ dengan elevasi sebesar 63 mdpl. Ketinggian lintasan 4 berkisar antara $63 \mathrm{mdpl}$ sampai $83 \mathrm{mdpl}$. Sudut kemiringan lereng dari lintasan 4 adalah 21,160 diklasifikasikan sebagai kemiringan lereng curam, yang menyebabkan lintasan ini berpotensi untuk longsor.

Gambar 7 merupakan hasil inversi citra dua dimensi penampang resistivitas pada lintasan 4 menggunakan metode geolistrik resistivitas konfigurasi Wenner-Schlumberger. Berdasarkan citra penampang resistivitas 2D (Gambar 7), kedalaman pengukuran mencapai 23,6 meter dengan iterasi sebanyak 15 kali dan RMS-error sebesar 8,9\%. Sedangkan rentang nilai resistivitas daerah penelitian bervariasi mulai dari $86,4 \Omega \mathrm{m}$ sampai $5682 \Omega \mathrm{m}$.

Jenis batuan pertama adalah batuan pasir lempungan dengan rentang nilai resistivitas berkisar 86,4 $\Omega \mathrm{m}-157 \Omega \mathrm{m}$. Jenis batuan kedua memiliki rentang nilai resistivitas berkisar 256 $\Omega \mathrm{m}-520 \Omega \mathrm{m}$ dapat diasumsikan sebagai batu pasir dan tanah penutup.

Jenis batuan ketiga dari warna hijau tua sampai cokelat memiliki rentang nilai resistivitas berkisar $945 \Omega \mathrm{m}-1718 \Omega \mathrm{m}$ dapat diasumsikan sebagai batu gamping. Jenis batuan keempat dari warna jingga sampai warna unggu gelap memiliki rentang nilai resistivitas berkisar 3125 $\Omega \mathrm{m}-5682 \Omega \mathrm{m}$, sehingga diasumsikan sebagai batuan granit.

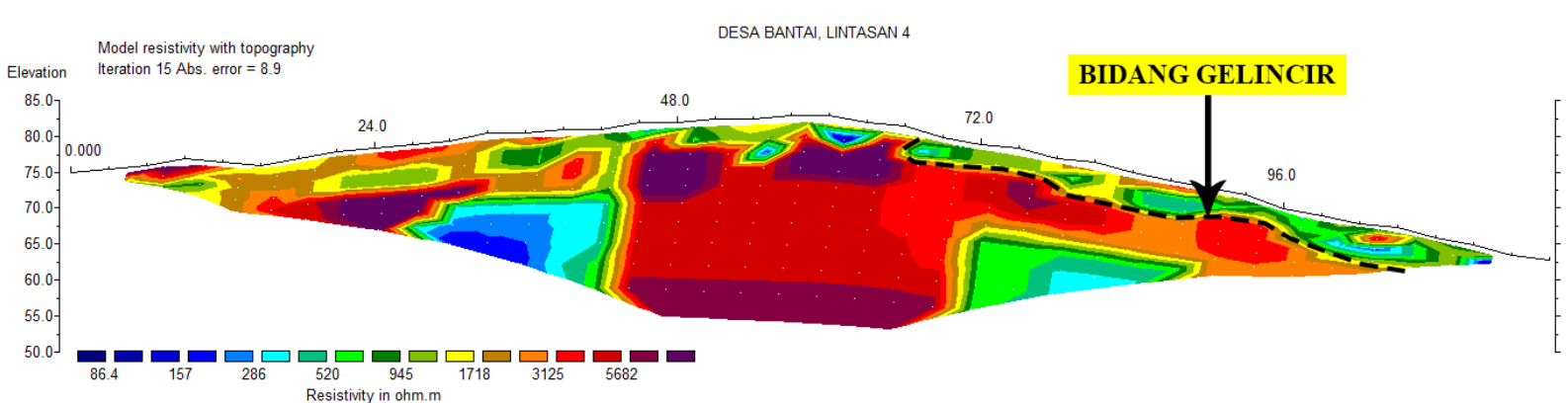

Gambar 7. Penampang resistivitas 2D pada lintasan 4

\subsection{Analisis Bidang Gelincir dan Tipe Tanah Longsor pada Empat Lintasan}

Hasil citra penampang resistivitas 2D menunjukkan bahwa daerah penelitian, Desa Bantai terdapat empat jenis batuan. Jenis batuan yang terdapat di daerah penelitian, yaitu batuan pasir lempungan, batu pasir dan tanah penutup, batu gamping dan granit.

Bidang gelincir pada setiap lintasan dapat diketahui dengan memasukkan nilai topografi pada hasil citra penampang resistivitas 2D. Gambar 4, Gambar 5, Gambar 6 dan Gambar 7 memperlihatkan bahwa penampang bidang gelincir ditandai dengan garis hitam putus-putus yang dicitrakan oleh lapisan berwarna hijau tua hingga cokelat. Bidang gelincir tanah longsor pada lintasan 1 memiliki rentang nilai resistivitas berkisar $1979 \Omega \mathrm{m}-3518 \Omega \mathrm{m}$, lintasan 2 
memiliki rentang nilai resistivitas berkisar 1604 $\Omega \mathrm{m}-3093 \Omega \mathrm{m}$, lintasan 3 memiliki rentang nilai resistivitas berkisar $1318 \Omega \mathrm{m}-2585 \Omega \mathrm{m}$ dan lintasan 4 memiliki rentang nilai resistivitas berkisar $945 \Omega \mathrm{m}-1718 \Omega \mathrm{m}$. Berdasarkan Tabel 1, nilai resistivitas batuan yang diprediksi sebagai bidang gelincir adalah batu gamping.

Pada setiap lintasan terdapat lapisan yang agak keras dan sejajar dengan muka lereng yaitu lapisan batu gamping. Lapisan batu gamping berada diantara dua lapisan yang memiliki nilai resistivitas yang kontras, yaitu antara lapisan tanah penutup dan batu pasir dengan lapisan batu granit. Batu gamping berperan sebagai penahan kestabilan lapisan tanah di area lereng bukit.

Secara geolistrik karakteristik bidang gelincir ditandai dengan adanya kecenderungan kontras nilai resistivitas yang cukup besar diantara lapisan batuan penyusun pada lereng. Hasil penelitian menunjukkan bahwa terdapat kekontrasan nilai resistivitas yang cukup besar antar lapisan batuan penyusun lereng bukit yaitu antara lapisan batu pasir dengan lapisan batu gamping yang berada di bawahnya.

Batu gamping memiliki porositas dan permeabilitas yang lebih kecil, sedangkan batu pasir dan tanah penutup mempunyai porositas dan permeabilitas yang lebih besar sehingga akan lebih mudah menyimpan dan meloloskan air. Meningkatnya kadar air dapat meningkatkan tekanan pori dan melemahkan kestabilan lereng. Apabila terjadi hujan, selain meloloskan air ke permukaan batu gamping, batu pasir dan tanah penutup juga menyimpan air yang menyebabkan bertambahnya beban batuan tersebut, sehingga akan mengurangi kuat geser lapisan yang berada di bawahnya.

Batu gamping hanya dapat menyimpan air tapi tidak dapat meloloskan air, sehingga apabila air yang masuk kepermukaan lereng tidak akan dapat menembus lapisan keras dan kedap air. Hal ini dapat menyebabkan air akan terakumulasi pada batuan tersebut yang menjadikan batuan tersebut licin dan mengurangi kuat geser dari batu gamping. Batu gamping yang licin akan berperan sebagai bidang tempat bergeraknya material pelapukan yang berada di atasnya maupun di bawahnya, sehingga dapat menyebabkan tanah longsor ke arah bawah maupun ke luar dari lereng bukit.

Selain dari faktor bidang gelincir, potensi terjadinya tanah longsor pada setiap lintasan juga dapat disebabkan oleh vegetasi di area penelitian. Pada area ini tidak terdapat pepohonan, sehingga air sangat mudah meresap ke bawah permukaan tanah.

Gambar 4, Gambar 5, Gambar 6 dan Gambar
7 memperlihatkan bahwa bentuk atau tipe bidang gelincir tanah longsor pada setiap lintasan adalah relatif berbentuk datar. Bentuk bidang gelincir ini disebut tipe translasi.

Kedalaman bidang gelincir tanah longsor pada setiap lintasan berbeda-beda. Kedalaman bidang gelincir tanah longsor pada lintasan 1 dan lintasan 2 terletak pada kedalaman 1 meter sampai 5 meter di bawah permukaan tanah. Kedalaman bidang gelincir tanah longsor pada lintasan 3 dan 4 terletak pada kedalaman 1 meter sampai 12 meter di bawah permukaan tanah. Bidang gelincir pada lintasan 1 dan lintasan 2 termasuk dalam golongan bidang gelincir dangkal, sedangkan bidang gelincir pada lintasan 3 dan lintasan 4 termasuk dalam golongan bidang gelincir dalam. Semakin dalam bidang gelincir, tingkat bahaya longsor akan semakin besar. Sebaliknya, semakin dangkal bidang gelincir, maka tingkat bahaya longsor semakin kecil.

Faktor lain yang mempengaruhi tingkat bahaya longsor adalah sudut kemiringan daerah penelitian. Sudut kemiringan lereng pada lintasan 1 adalah 21,610, lintasan 2 adalah $20,96^{\circ}$, lintasan 3 adalah $18,97^{\circ}$ dan lintasan 4 adalah $21,16^{\circ}$. Sudut kemiringan lereng yang pada setiap lintasan diklasifikasikan ke dalam kemiringan lereng curam, sehingga berpotensi untuk longsor. Kemiringan lereng sangat berpengaruh terhadap longsor, dimana semakin curam lereng maka akan berpotensi terjadinya tanah longsor yang besar dan cepat. Kemiringan lereng merupakan unsur topografi yang paling berpengaruh terhadap aliran permukaan dan erosi tanah. Sudut kemiringan lintasan 1 lebih besar dibandingkan dengan lintasan 2, lintasan 3 dan lintasan 4, sehingga potensi bahaya longsor yang besar terdapat pada lintasan 1 . Ini sesuai dengan keadaan di lapangan, dimana di lintasan 1 telah terjadi longsor pada jarak 99 meter sampai 111 meter dengan ketinggian sekitar 2,5 meter yang terjadi pada tahun 2018 yang ditandai dengan kotak berwarna hitam pada Gambar 4.

\section{Kesimpulan}

Berdasarkan hasil interpretasi penampang resistivitas 2 dimensi, maka dapat disimpulkan bahwa batuan yang menjadi bidang gelincir tanah longsor dari empat lintasan di Desa Bantai, Kecamatan Bonti, Kabupaten Sanggau yaitu batu gamping dengan nilai resistivitas antara $945 \Omega \mathrm{m}$ sampai $3518 \Omega \mathrm{m}$. Berdasarkan interpretasi nilai resistivitas bidang gelincir tanah longsor pada keempat lintasan relatif berbentuk bidang datar, sehingga tipe tanah longsor di daerah tersebut adalah tipe translasi. 


\section{Ucapan Terimakasih}

Penulis mengucapkan terimakasih kepada Camat Bonti Bapak Darmikus, S.Sos yang telah memberikan izin untuk melakukan penelitian serta kepada Pemda Kayong Utara dan Comdev dan Outreaching atas beasiswa yang diberikan di Prodi Geofisika FMIPA Universitas Tanjungpura.

\section{Daftar Pustaka}

[1] Badan Nasional Penanggulangan Bencana, BNPB Kalbar, Kajian Resiko Bencana Kalimantan Barat Tahun 2016-2020, Pontianak, 2015.

[2] Rahman, A., Hidayat, S. dan Indriawan, B., Pemetaan Area Rawan Longsor Di Daerah Songgoriti Kecamatan Batu Kota Batu Dengan Menggunakan Metode Geoilistrik Wenner, Jurusan Fisika Universitas Negeri Malang, Malang, 2013.

[3] Darsono., Nurlaksito, B. dan Legowo, B., Identifikasi Bidang Gelincir Pemicu Bencana Tanah Longsor Dengan Metode Resistivitas 2 Dimensi Di Desa Pablengan Kecamatan Matesih Kabupaten Karanganyar, Jurusan Fisika Fakultas MIPA Universitas Sebelas Maret Surakarta, Indonesian Journal of Applied Physics, 2(1), 57-66, 2012.

[4] Wakhidah, N., Khumaedi., dan Dwijananti, P., Identifikasi Pergerakan Tanah Dengan Aplikasi Metode Geolistrik Konfigurasi Wenner-Schlumberger di Deliksari Gunung Pati Semarang, Unnes Physics Journal, 3(1), 2014.

[5] Heradian, E.A. dan Arman, Y., Pendugaan Bidang Gelincir Tanah Longsor di Desa Aruk Kecamatan Sajingan Besar Kabupaten Sambas dengan Menggunakan Metode Tahanan Jenis, FMIPA Untan, Pontianak, 3(2), 56-61, 2015.

[6] Lismalini., Akmam dan Sudiar, N.Y., Penyelidikan Bidang Gelincir Menggunakan Metoda Geolistrik Tahanan Jenis Konfigurasi Schlumberger di Desa Kampung Manggis Kecamatan Padang Panjang Barat. Pillar of Physics., 1, 25-32, 2014.

[7] Telford, W.M., Geldart, L.P., Sheriiff, R.E. dan Keys, D.A., Applied Geophysics, Cambridge University Press., London, 1990.

[8] Romadon, I., Identifikasi Bidang Gelincir di Dusun Dukuh, Desa Koripan, Kecamatan Matesih, Kabupaten Karanganyar, Menggunakan Metode Geolistrik Resistivitas Konfigurasi Wenner Alfa, FMIPA Universitas Sebelas Maret, Surakarta, 6(2), 88-96, 2016.

[9] Adhi, M.A., Metode Geolistrik, Universitas Negeri Semarang, Semarang, 2003.
[10] Reynolds, J.M., An Introduction to Applied and Environmental Geophysics, John Wiley and Sons Ltd., England, 1997.

[11] Loke, M.H., Elektrical Imaging Surveys for Environmental and Engineering Studies; A Practical Guide to 2-D and 3-D Surveys, Penang, Malaysia, 1999.

[12] Google Earth Pro, Tempat Penelitian Desa Bantai Kecamatan Bonti Kabupaten Sanggau, http://www.google-earthpro.id.uptodown.com, (1 Desember 2018).

[13] Supriatna, S., Margono, U., Sutrisno., Pieters, P.E. dan Langford, R.P., Peta Geologi Lembar Sanggau, Kalimantan, Pusat Penelitian dan Pengembangan Geologi, Bandung, 1993. 


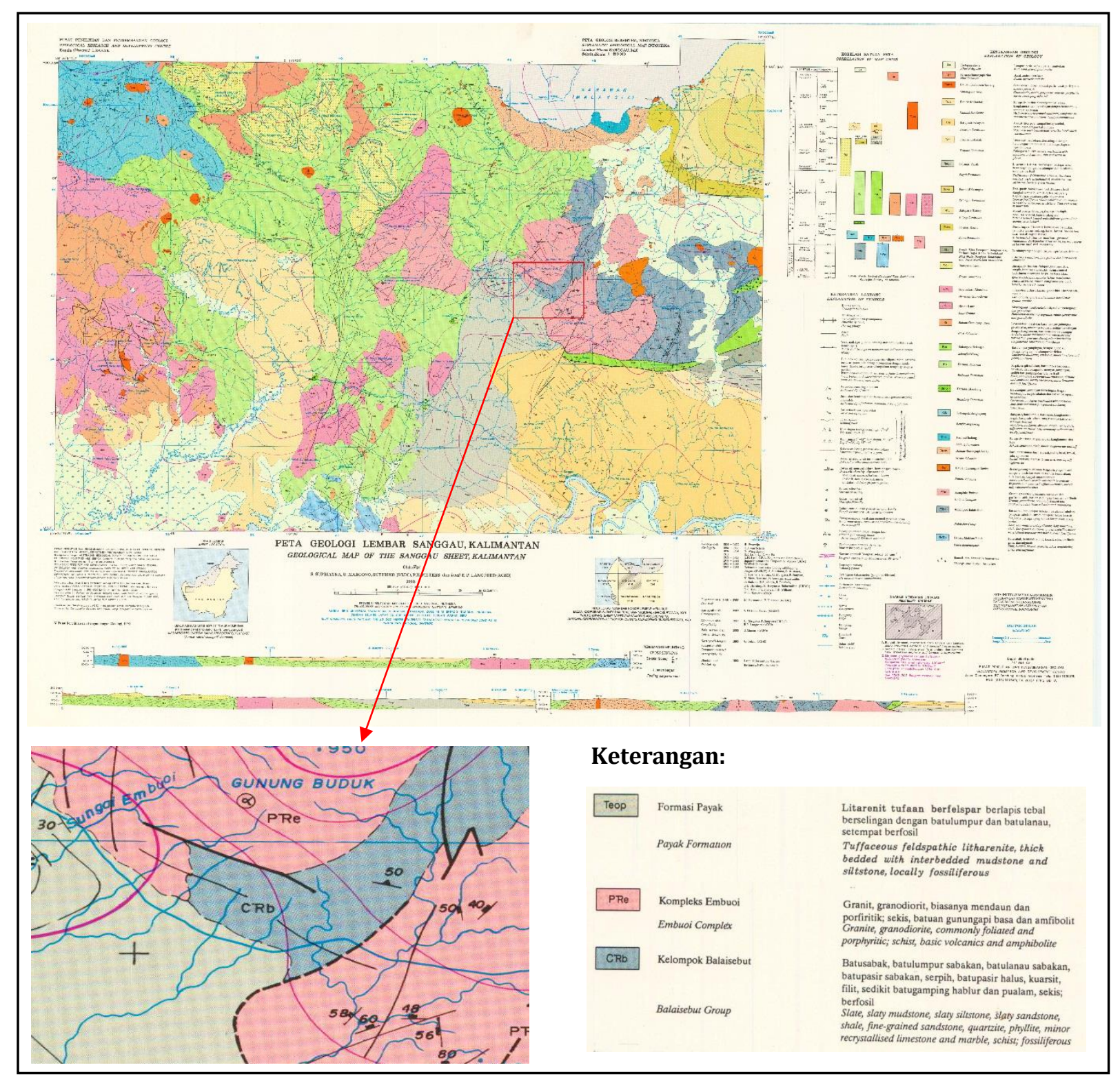

Gambar 8. Peta geologi lembar Sanggau, Kalimantan Barat [13] 